\title{
Non-metric dental variation of Sakishima Islanders, Okinawa, Japan: a comparative study among Sakishima and neighboring populations
}

\author{
Kuniaki HANEJI ${ }^{1}$, Tsunehiko HANIHARA ${ }^{2}$, Hajime SUNAKAWA ${ }^{3}$, \\ Takashi TOMA $^{1}$, Hajime ISHIDA ${ }^{1 *}$ \\ ${ }^{1}$ Department of Anatomy, Faculty of Medicine, University of the Ryukyus, Uehara 207, Nishihara, Okinawa, 903-0215 Japan \\ ${ }^{2}$ Department of Anatomy and Biological Anthropology, Saga Medical School, 5-1-1 Nabeshima, Saga, 849-8501 Japan \\ ${ }^{3}$ Department of Oral and Maxillofacial Functional Rehabilitation, Faculty of Medicine, University of the Ryukyus, \\ Uehara 207, Nishihara, Okinawa, 903-0215 Japan
}

Received 6 February 2006; accepted 9 August 2006

\begin{abstract}
Twenty-four non-metric tooth crown traits of Miyako and Ishigaki Islanders, from the southernmost Ryukyu Islands, were investigated and compared with those of neighboring populations. The frequency of double-shoveling in Sakishima samples, and especially, Ishigaki Island, is lower than that found among Atayal people (Taiwan) and main-island Japanese. The frequencies of protostylid and cusp 6 in Miyako and Ishigaki Islanders are comparable to those in Hokkaido Ainu and lower than in main-island Japanese and Atayal. Miyako and Ishigaki Islanders, as well as other Ryukyuans, are basically more similar to main-island Japanese than to Ainu, while being situated between main-island Japanese and Ainu in terms of both mean measure of divergence (MMD) and R-matrix methods. However, Ishigaki and Miyako Islanders are relatively close to Hokkaido Ainu among Ryukyu people and main-island Japanese, as suggested in some previous preliminary studies. The estimated Fst (the ratio of among-group variation to total variation), using an average heritability rate $=0.55$ for the non-metric tooth crown traits used in this study, displayed low levels of inter-regional variation, as already indicated in analyses of genetic, cranial and dental metric data. Meanwhile, the relatively large diversity of Ryukyu Islanders based on Fst suggested long-term isolation or poor intra-island contact among the Ryukyu Islands. The lower observed variation compared with the expected variation in most Ryukyu samples may reflect a greater degree of genetic drift in the Ryukyu Island chain.
\end{abstract}

Key words: Miyako, Ishigaki, Ryukyuans, non-metric dental variation, population diversity

\section{Introduction}

The Ryukyu Islands are scattered between the main Japanese islands and Taiwan (Figure 1). The nature and ethnicity of Ryukyu Islanders has been described and discussed for more than 100 years (e.g. Hawks and Perry, 1856; von Baelz, 1911). In the field of biological anthropology, many researchers have also been interested in the prehistoric and historic populations of these islands.

Many morphological and genetic studies have suggested that Ryukyu Islanders are generally more similar to mainisland Japanese than to the Ainu and Jomon, who were hunter-gatherers in the Japanese archipelago from 10000 to 2000 BP (Ikeda, 1974, 1998; Tagaya and Ikeda, 1976; Dodo et al., 1998, 2000; Hatta et al., 1999; Manabe et al., 1999; Higa et al., 2003; Fukumine et al., 2006), while close relationships between Ryukyu Islanders and Jomon-Ainu samples have also been reported by many researchers (Hanihara et al., 1974; Hanihara, 1991; Matsumura 1994; Omoto and

\footnotetext{
* Corresponding author. e-mail: ishidaha@med.u-ryukyu.ac.jp phone: +81-98-895-1100; fax: +81-98-895-1400

Published online 31 October 2006

in J-STAGE (www.jstage.jst.go.jp) DOI: 10.1537/ase.060206
}

Saitou, 1997; Yamashita et al., 2001; Watanabe et al., 2004; Matsumura and Hudson, 2005). However, the problem is not whether Ryukyu Islanders are close to the Ainu, but why Ryukyu Islanders are relatively close to the Ainu (Fukumine et al., 2006), because modern populations in the Japanese archipelago should essentially have Jomon traits, as indicated by recent genetic studies (Umetsu et al., 2005; Hammer et al., 2006). Thus, we consider that the basic view of the 'dual structure model' for Japanese population history proposed by K. Hanihara (1991) is valid for the Japanese archipelago, and remains so (Saitou, 2005; Nagaoka and Hirata, 2006; Ossenberg et al., 2006).

Several significant Late Pleistocene human remains have been found on Okinawa Island, and on Kumejima and Miyako Islands (Suzuki and Hanihara, 1982; Sakura, 1988). Although later prehistoric and historic human remains have been found on Okinawa Island, few prehistoric human skeletons have been recovered from the Sakishima Islands, including Miyako and Ishigaki Islands (Doi, 2003).

Dental characteristics have been studied for not only human evolutionary research, but also for the reconstruction of population history because of intra-populational homogeneity and inter-populational variation (Scott and Turner, 1997). 


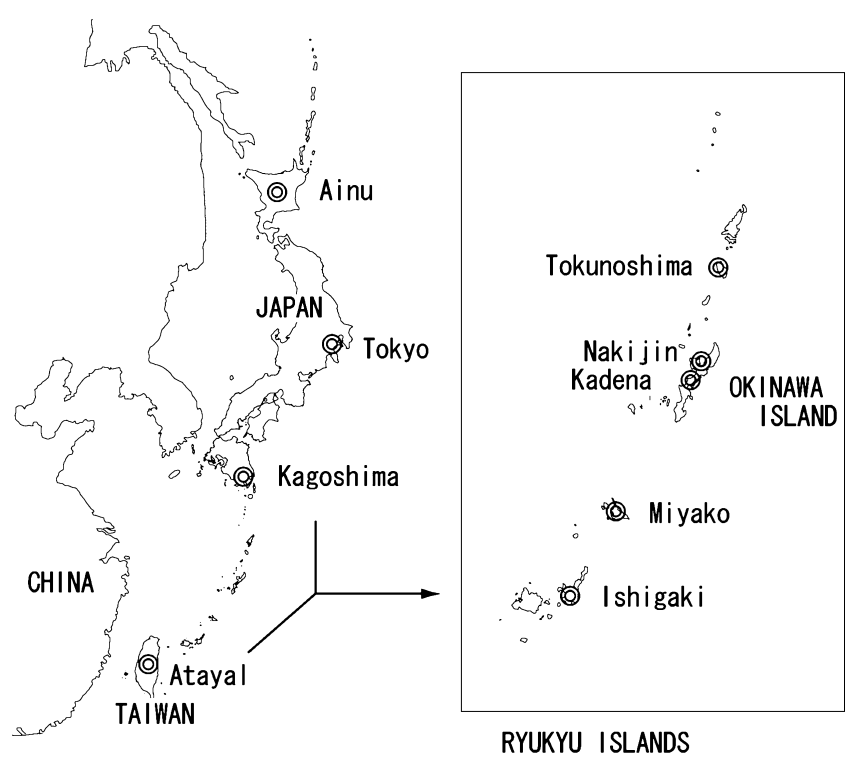

Figure 1. Map of East and Southeast Asia showing the geographical locations of the Ryukyuans and other Asians used in this study.

Hanihara et al. (1974) collected dental casts from the Nakijin people in the northern part of Okinawa Island and showed the intermediate position of Okinawa Islanders between main-island Japanese and Ainu. Recently, non-metric dental variations among Okinawa and Tokunoshima Islands were investigated by collecting dental casts from the Kadena people in the central part of Okinawa Island (Higa et al., 2003). The relatively large intra-regional variation in Ryukyu Islanders was considered in that study; however, we also considered that the whole intra-regional variation, including the southern part of the Ryukyu Islands, e.g. Miyako and Ishigaki Islands, should be investigated to elucidate Ryukyuan diversity and population history.

The Sakishima Islands, including Miyako and Ishigaki Islands, are located about $300-500 \mathrm{~km}$ southwest of Okinawa Island, as shown in Figure 1. Late Pleistocene human remains were recovered at Pinza-Abu (Goat Cave), on Miyako Island, between 1979 and 1983 (Sakura, 1985). The prehistoric age of the Sakishima area consisted of two hunter-gatherer cultures from 4000 to $1500 \mathrm{BP}$, which is somewhat different from Okinawa and Amami Islands, the culture of which is closely related to the Jomon (Ikeda, 2005). From the 10th to 12th centuries AD, the protohistoric cultures of the Okinawa-Amami and Sakishima areas were joined to make the Ryukyu cultural area.

The dentitions of Miyako and Ishigaki Islanders have already been briefly reported by Hanihara (1991) and Manabe et al. (2001, 2003). Hanihara (1991) pointed out that the early Modern people of Sakishima retained Jomon-like dentition. Manabe et al. $(2001,2003)$ agreed with the supposed gene flow from the Japanese main islands, based on the clinal dental variations from north to south in the Ryukyu Islands after the Jomon period. Unfortunately, however, the sample size was small and the origins of the samples were not always clear.

Here, we collected sufficient numbers of dental casts of native modern Sakishima Islanders from Miyako and Ishigaki Islands to investigate 24 non-metric dental characters, including premolar traits (Higa et al., 2003). The purposes of this study were to present these 24 non-metric dental traits of the Miyako and Ishigaki Islanders, and to evaluate more precisely the intra- and inter-regional dental variations of all Ryukyu Islanders.

\section{Materials and Methods}

We gathered plaster casts of permanent dentition from 202 pupils (107 males and 95 females) of Taira Junior High School, situated in the downtown area of Miyakojima City, Miyako Island, in 2004-2005, and from 146 pupils (73 males and 73 females) of Ishigaki and Ishigaki Second Junior High Schools in the downtown area of Ishigaki City, Ishigaki Island, in 2005 (Table 1, Figure 1). The subjects were selected as individuals with no admixture of ancestors from other islands for at least three generations, as reported in our previous study (Higa et al., 2003). The Ethical Committee of the University of the Ryukyus approved the protocol of this study and all subjects gave informed consent.

The comparative samples came from the following peoples: Kadena and Nakijin of Okinawa Island and Tokunoshima of the Ryukyu Islands, main-island Japanese in Tokyo and Kagoshima, Hokkaido Ainu on Hokkaido Island, Atayal in Taiwan, and Afghanistan in West Asia (see Table 1 in Higa et al., 2003), as shown in Figure 1. We included the Afghanistan sample in order to use it as an outgroup and to calculate inter-regional variation.

The first author (K.H.) scored all 24 non-metric dental traits used in this study as present or absent for the Miyako and Ishigaki samples, following the criteria of Higa et al. (2003). The comparative samples were recorded following the same standards as Higa (Higa et al., 2003). Higa et al. (2003) assessed intra-observer errors of the 24 traits by phi coefficient to confirm that the errors were quite low.

The first author scored the 24 non-metric dental traits of the Kadena dental casts independently five times in 20052006, and compared the individual data with the data scored by Higa (Higa et al, 2003) to assess and reduce intra- and inter-observer errors according to Fisher's exact probability test. We confirmed that the errors were insignificant. When

Table 1. Samples collected in this study

\begin{tabular}{ccll}
\hline $\begin{array}{c}\text { Sample } \\
\text { name }\end{array}$ & $n(\mathrm{M} / \mathrm{F})^{1}$ & \multicolumn{1}{c}{ Provenience (year) } & Preservation \\
\hline Miyako & $202(107 / 95)$ & $\begin{array}{l}\text { Miyako (2004-2005) from } \\
\text { Miyako Island located } \\
\text { about 300 km southwest of } \\
\text { Okinawa Island }\end{array}$ & $\begin{array}{l}\text { Univ. of the } \\
\text { Ryukyus }\end{array}$ \\
\hline Ishigaki & $146(73 / 73)$ & $\begin{array}{l}\text { Ishigaki (2005) from Ishi- } \\
\text { gaki Island located about } \\
\text { 450 km southwest of Oki- } \\
\text { nawa Island }\end{array}$ & $\begin{array}{l}\text { Univ. of the } \\
\text { Ryukyus }\end{array}$ \\
& & & \\
\hline
\end{tabular}

\footnotetext{
${ }^{1}$ M: male, F: female.

${ }^{2}$ Figures in parentheses show the years when the samples were collected.
} 
the traits were scored after a one-year interval, the intraobserver errors of a few traits, e.g. the deutero-proto relationship $(p=0.2152)$, were relatively large, but insignificant. The inter-observer errors of the all traits were also insignificant, while the lingual paracone tubercle showed a relatively low probability $(p=0.1902-0.2420)$.

The frequencies of the 24 non-metric dental traits were calculated based on pooled-sex and individual counts, as used in a previous study (Higa et al., 2003). Fisher's exact probability test was used to evaluate the frequency differences between Miyako and Ishigaki and the comparative samples, respectively. The modified Smith's mean measure of divergence (MMD) was applied to calculate the estimated biological distance between the pairs of samples used (Sjøvold, 1973). MMD has been commonly used for nonmetric cranial and dental traits, and its efficacy has been summarized in a previous paper (Hanihara et al., 2003).

The multidimensional scaling method (Sneath and Sokal, 1973) and the neighbor-joining method (Saitou and Nei, 1987), commonly used in phylogenetic analyses, were applied to the distance matrix in order to graphically represent the mutual relationships.

In addition to MMDs, we analyzed the pattern of affinities among groups, calculating the standard relationship matrix (R-matrix) (Relethford and Blangero, 1990). Using the diagonal elements of the R-matrix $\left(r_{i i}\right)$, moreover, we can analyze variations within and among populations (Harpending and Ward, 1982; Relethford and Blangero, 1990; Relethford and Harpending, 1994).

The R-matrix method was originally developed to analyze frequencies of genetic traits (Harpending and Ward, 1982; Relethford, 1994). However, the R-matrix method can also be applied to quantitative morphological traits using the model developed by Relethford and Blangero (1990) (Relethford, 1991, 1994; Relethford and Harpending, 1994; Powell and Neves, 1999; Steadman, 2001; González-José et al., 2003; Roseman and Weaver, 2004; Stojanowski, 2004, 2005; Hanihara and Ishida, 2005; Schillaci and Stojanowski, 2005). Several different approaches have been used to apply the R-matrix method to non-metric morphological data. Hallgrímsson et al. (2004) used non-metric morphological trait frequencies as analogous to allele frequencies to compute the R-matrix and other genetic parameters. Another approach is based on the assumption that non-metric traits are measured as the underlying or latent distribution of liabilities for each trait. This model assumes that trait liability shows a normal distribution, and is dichotomized by the imposition of a threshold. Recent theoretical developments from Bayesian statistics, have given estimates of liabilities via the Gibbs sampler, using the Markov chain Monte Carlo method. Liabilities estimated in this way are then used to calculate the R-matrix (Blangero and Williams-Blangero, 1993; Leigh and Konigsberg, 1996; Leigh et al., 2004).

In this study, we calculated the R-matrix and related parameters under the assumption that non-metric trait frequencies behave like allele frequencies because of the very high correlation between the R-matrix and other distance measures, such as MMDs, B-squared distance, and the Mahalanobis distance based on tetrachoric correlation coefficients, etc. However, the matrix correlation is not necessar- ily a theoretical justification, so the results of this analysis should be interpreted cautiously.

Given any attribute data or trait frequency data, the variance-covariance matrix of population relationships, known as the standard relationship matrix (or R matrix) can be calculated. The elements of the $\mathrm{R}$ matrix are estimated for any given trait as

$$
r_{i j}=\left(p_{i}-\bar{p}\right)\left(p_{j}-\bar{p}\right) / \bar{p}(1-\bar{p})
$$

where $p_{i}$ and $p_{j}$ are trait frequencies in populations $i$ and $j$, and $\bar{p}$ is the mean trait frequency over all populations (Relethford and Harpending, 1994; Hallgrímsson et al., 2004). The $R$ matrix obtained for each trait is then averaged over all traits. Fst, the ratio of among-group variation to total variation, is defined as:

$$
F s t=\Sigma w_{i} r_{i i}
$$

where $w_{i}$ is the weighting factor for the relative size of population $i$, defined as:

$$
w_{i}=N_{i} / \Sigma N_{j} \text {, }
$$

and $N_{j}$ is the effective size of population $j$. In order to make the Fst statistics (or R-matrix) method 'model-bound' (Relethford, 1994), the population sizes are required. This method assumes that trait heritabilities are equal to 1 . This method of estimating $F_{s t}$ is referred to as minimum Fst (Relethford, 1994). Because phenotypic traits are not completely under genetic control, the actual Fst value can be obtained using estimates of the average heritability of phenotypic traits, or $h^{2}$, using the following formula (Relethford, 1994):

$F_{s t}=$ minimum $F_{s t} /\left[\right.$ minimum $\left.F_{s t}+h^{2}\left(1-\operatorname{minimum} F_{s t}\right)\right]$.

Because phenotypic traits are not completely under genetic control, the actual values of parameters based on the R-matrix method, such as inter- and intra-regional variations, should be assessed using estimates of the average heritability of phenotypic traits. Previous studies have reported the heritability estimates of tooth crown traits based on family and twin studies (Biggerstaff, 1970, 1973; Berry, 1978; Hillson, 1996; Scott and Turner, 1997). Mizoguchi (1977) reported the heritability of 14 crown traits for a Japanese population. The mean heritability rate was $\sim 0.55$ (range $0.12-0.75$ ). If heritability is a population-specific value, however, the estimates cannot be applied to other samples and groups, or across the board. Several researchers studying twin series from different populations arrived at similar heritability estimates for some traits (Hanihara et al., 1975; Blanco and Chakraborty, 1977; Mizoguchi, 1977; Scott and Potter; 1984; Townsend et al., 1992). We have surveyed several studies (Sofaer et al., 1972; Mizoguchi, 1977; Scott and Potter, 1984; Townsend et al., 1992) and found that most estimates of heritability rates for crown traits fall between 0.50 and 0.80 (Scott and Turner, 1997). We therefore tentatively selected an estimate of average heritability for nonmetric crown traits of 0.55 . This estimate may be conservative, or at least not an overestimate. Since the heritability of metric cranial and dental traits was estimated as 0.55 (Relethford, 1994; Hanihara and Ishida, 2005), the results obtained in this study can be directly compared with previous works that have used the R-matrix method.

Although estimated Fst values vary, based on an estimate of average heritability (Relethford, 1994), the estimated Fst are reasonably robust as long as the average heritability is 
moderate to high (Roseman and Weaver, 2004).

\section{Results}

Table 2 summarizes the observed and affected numbers and frequencies of the 24 non-metric dental traits among Miyako and Ishigaki Islanders and the comparative samples.

Fisher's exact probability test was performed for the Miyako and Ishigaki and the comparative samples, respectively. There are three significant traits between the Miyako and Ishigaki samples: the lingual paracone tubercle, the oblique ridge and the deutero-proto relationship. Among the Ryukyu Islands, eight traits in Kadena were found to be significantly different from Miyako, although only two to three traits in Nakijin and Tokunoshima were recognized, partly because of the small sample size. From Ishigaki Island, five in Kadena, two in Nakijin and seven in Tokunoshima were significantly different. Five or six traits in main-island Japanese and seven or eight traits in Hokkaido Ainu were sig- nificantly different from both Miyako and Ishigaki, while the Afghanistan sample has many significant traits.

For the convenience of univariate comparisons, we drew the frequency patterns of several populations, excluding the Afghanistan sample, as shown in Figure 2 and Figure 3.

The Miyako and Ishigaki Islanders have higher frequencies of shoveling than Hokkaido Ainu, but lower than the Atayal sample. The frequencies of double shoveling showed the same tendency, but are more conspicuous in Ishigaki Islanders, who have a significantly lower incidence than not only Atayal and main-island Japanese, but also Kadena. The frequency of the lingual paracone tubercle is the lowest in the Ishigaki Islanders, and a geographical cline from north to south is roughly seen. The lowest frequency of cusp 5 in the Atayal sample is significantly different from that found for the Miyako and Ishigaki Islanders. The frequency patterns of the protostylid, deflecting wrinkle and cusp 6 in the Miyako and Ishigaki Islanders, are similar to those in Hokkaido Ainu, while those in the Kadena, Tokyo and Atayal samples

Table 2. Frequencies of non-metric tooth crown characters and Fisher's exact probability test for the difference of the trait frequencies between the Miyako and Ishigaki samples and the other comparative samples (per individual, sex combined)

\begin{tabular}{|c|c|c|c|c|}
\hline Population & $\begin{array}{c}\text { Shoveling } \\
\text { (UI1) } \%(\mathrm{~A} / \mathrm{O})\end{array}$ & $\begin{array}{l}\text { Double-shoveling } \\
\text { (UI1) \% (A/O) }\end{array}$ & $\begin{array}{c}\text { Peg-shaped } \\
\text { (UI2) \% (A/O) }\end{array}$ & $\begin{array}{l}\text { Mesial canine ridge } \\
\text { (UC) } \%(\mathrm{~A} / \mathrm{O})\end{array}$ \\
\hline Miyako & $92.9(169 / 182)$ & $72.1(129 / 179)$ & $3.0(6 / 200)$ & $3.3(5 / 153)$ \\
\hline Ishigaki & $92.2(118 / 128)$ & $61.7(79 / 128)$ & $0.7(1 / 140)$ & $2.0(2 / 100)$ \\
\hline Kadena & $94.4(187 / 198)$ & 79.4 (158/199)\#\#\# & $5.2(11 / 211) \#$ & $4.3(8 / 185)$ \\
\hline Nakijin & $96.3(52 / 54)$ & $83.6(46 / 55) \# \#$ & $3.1(2 / 64)$ & $5.8(3 / 52)$ \\
\hline Tokunoshima & $93.3(56 / 60)$ & 78.4 (58/74)\# & $6.4(5 / 78) \#$ & $1.2(1 / 84)$ \\
\hline Kagoshima & $93.9(62 / 66)$ & $84.5(71 / 84)^{*} \# \# \#$ & $3.3(3 / 90)$ & $8.0(7 / 88)$ \\
\hline Tokyo & $95.6(86 / 90)$ & 80.7 (75/93)\#\# & $1.9(2 / 106)$ & $8.1(7 / 86)$ \\
\hline Ainu & $73.3(33 / 45)^{* * * \# \# ~}$ & $41.0(25 / 61)^{* * * \# \#}$ & $2.4(2 / 84)$ & $0.0(0 / 58)$ \\
\hline Atayal & $100.0(67 / 67)^{* \#}$ & $82.3(65 / 79) \# \#$ & $3.3(3 / 92)$ & $5.9(5 / 85)$ \\
\hline Afghanistan & 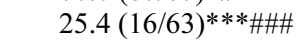 & $31.8(28 / 88) * * * \# \# \#$ & $1.1(1 / 89)$ & $7.3(6 / 82)$ \\
\hline Population & $\begin{array}{c}\text { Interstitial tubercle } \\
\text { (UP1) mesial \% (A/O) }\end{array}$ & $\begin{array}{l}\text { Interstitial tubercle } \\
\text { (UP1) distal \% (A/O) }\end{array}$ & $\begin{array}{c}\text { Interstitial tubercle } \\
\text { (UP2) mesial \% (A/O) }\end{array}$ & $\begin{array}{l}\text { Interstitial tubercle } \\
\text { (UP2) distal \% (A/O) }\end{array}$ \\
\hline Miyako & $47.0(85 / 181)$ & $8.5(16 / 188)$ & $23.9(42 / 176)$ & $8.1(14 / 173)$ \\
\hline Ishigaki & $43.2(60 / 139)$ & $5.7(8 / 141)$ & $20.6(28 / 136)$ & $13.1(17 / 130)$ \\
\hline Kadena & $51.4(91 / 177)$ & $6.6(11 / 166)$ & $24.3(46 / 189)$ & $10.3(19 / 185)$ \\
\hline Nakijin & $57.4(35 / 61)$ & $18.2(5 / 61)$ & $27.3(15 / 55)$ & $11.5(6 / 52)$ \\
\hline Tokunoshima & $51.9(41 / 79)$ & $9.3(7 / 75)$ & $30.3(23 / 76)$ & $14.7(10 / 68)$ \\
\hline Kagoshima & 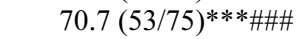 & $14.3(10 / 70) \#$ & $28.8(19 / 66)$ & $17.4(12 / 69)^{*}$ \\
\hline Tokyo & $63.7(65 / 102) * * \# \#$ & $8.5(8 / 94)$ & $21.6(19 / 88)$ & $12.5(10 / 80)$ \\
\hline Ainu & $48.4(30 / 62)$ & $16.7(9 / 54) \#$ & $23.9(11 / 46)$ & $21.7(10 / 46)^{*}$ \\
\hline Atayal & $46.2(43 / 93)$ & $6.0(5 / 84)$ & $22.0(20 / 91)$ & $7.1(6 / 84)$ \\
\hline Afghanistan & 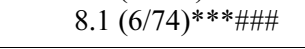 & $6.6(5 / 76)$ & $4.2(3 / 71)^{* * * \# \#}$ & $10.1(7 / 69)$ \\
\hline Population & $\begin{array}{l}\text { Carabelli's tubercle } \\
\text { (UM1) \% (A/O) }\end{array}$ & $\begin{array}{c}\text { Lingual paracone tubercle } \\
\text { (UM1) \% (A/O) }\end{array}$ & $\begin{array}{c}\text { Protoconule } \\
(\mathrm{UM} 1) \%(\mathrm{~A} / \mathrm{O})\end{array}$ & Cusp 5 (UM1) \% (A/O) \\
\hline Miyako & $4.2(8 / 190)$ & $62.2(46 / 74) \#$ & $34.7(41 / 118)$ & $37.3(28 / 75)$ \\
\hline Ishigaki & $3.0(4 / 133)$ & $44.3(35 / 79) *$ & $24.1(27 / 112)$ & $43.0(37 / 86)$ \\
\hline Kadena & $3.6(7 / 196)$ & 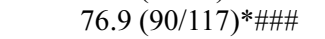 & $23.4(37 / 158) *$ & $45.0(54 / 120)$ \\
\hline Nakijin & $1.6(1 / 61)$ & 77.8 (38/49)\#\#\# & $24.1(14 / 58)$ & $46.8(22 / 47)$ \\
\hline Tokunoshima & $5.8(4 / 69)$ & $71.0(22 / 31) \#$ & $39.6(21 / 53) \#$ & $38.9(14 / 36)$ \\
\hline Kagoshima & $8.5(6 / 71)$ & $75.0(12 / 16) \#$ & $27.8(15 / 54)$ & $36.8(14 / 38)$ \\
\hline Tokyo & $4.9(5 / 103)$ & 73.3 (66/90)\#\#\# & $35.3(36 / 102)$ & $40.5(34 / 84)$ \\
\hline Ainu & $1.1(1 / 89)$ & 75.0 (39/52)\#\#\# & $35.1(20 / 57)$ & $23.1(12 / 52) \#$ \\
\hline Atayal & $2.3(2 / 87)$ & $58.2(39 / 67)$ & $28.0(21 / 75)$ & $15.7(11 / 70)^{* * \# \# \# ~}$ \\
\hline Afghanistan & $5.0(3 / 60)$ & $20.6(7 / 34)^{* * * \#}$ & $0.0(0 / 38)^{* * * \# \#}$ & 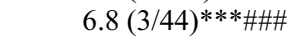 \\
\hline
\end{tabular}

Numbers in parentheses show the affected/observed sample number.

Miyako: $* p<0.05, * * p<0.01, * * * p<0.001$.

Ishigaki: \# $p<0.05, \# \# p<0.01$, \#\#\# $p<0.001$. 
show another pattern. The frequencies of the protostylid and cusp 6 in the Miyako and Ishigaki Islanders are comparable to those in Hokkaido Ainu and lower than those in the other three populations. On the other hand, the Miyako sample has the highest frequency of deflecting wrinkle.

Because of the small sample size for a few populations, we had to exclude frequency data of the lingual paracone tubercle, oblique ridge, protostylid, deflecting wrinkle, distal trigonid crest, and groove pattern, as in the previous study (Higa et al., 2003).

The modified MMDs were calculated using 18 non-metric dental traits for the ten populations, and the distance matrix and standard deviations are given in Table 3. The MMD between the Miyako and Ishigaki samples is only 0.002 and therefore insignificant. The next closest to Miyako and Ishigaki is the Kadena sample. The MMDs among the Kadena, Nakijin and Tokunoshima samples are small (0.002-0.024) and insignificant. Ryukyuans are generally closer to mainisland Japanese and Atayal than to Hokkaido Ainu. Interest- ingly, the closest to Hokkaido Ainu is Ishigaki (0.0071) and the next closest is Miyako (0.0081) and Tokunoshima (0.0083). The Afghanistan sample is the most remote.

The multidimensional scaling method of the MMD matrix, listed in Table 3, was applied. The Afghanistan sample was excluded in this case because of its extreme isolation. A two-dimensional display of the first and second axes is shown in Figure 4. The first and second axes explained $76.9 \%$ and $15.4 \%$ of total variation, respectively. The Hokkaido Ainu sample is situated in the left side, which showed the outliers. The Atayal sample is also somewhat isolated in the lower right portion of the figure. Both the Kagoshima and the Tokyo samples are plotted on the right side while the Ryukyu samples, loosely connected to each other, are located between the main-island Japanese and the Hokkaido Ainu. Although the Nakijin and Kadena samples are much closer to main-island Japanese, the Ishigaki and the Miyako samples are relatively near to the Hokkaido Ainu sample.

The neighbor-joining method was applied to the MMD

Table 2. (continued)

\begin{tabular}{|c|c|c|c|c|}
\hline Population & $\begin{array}{l}\text { Oblique ridge } \\
(\mathrm{UM} 1) \%(\mathrm{~A} / \mathrm{O})\end{array}$ & $\begin{array}{c}\text { Hypocone } \\
\text { (UM2)\% } \% \text { (A/O) }\end{array}$ & $\begin{array}{l}\text { Lingual cusp } \\
(\mathrm{LP} 1) \%(\mathrm{~A} / \mathrm{O})\end{array}$ & $\begin{array}{l}\text { Deutero-proto relationship } \\
(\mathrm{LP} 1) \%(\mathrm{~A} / \mathrm{O})\end{array}$ \\
\hline Miyako & $23.5(16 / 68) \# \#$ & $96.0(119 / 124)$ & $97.5(194 / 199)$ & $29.6(58 / 196) \#$ \\
\hline Ishigaki & $45.3(34 / 75)^{* *}$ & $96.9(93 / 96)$ & $95.2(138 / 145)$ & $18.6(27 / 145)^{*}$ \\
\hline Kadena & $44.0(48 / 109)^{* *}$ & $98.5(132 / 134)$ & $91.2(197 / 216)^{* *}$ & $19.5(34 / 174)^{*}$ \\
\hline Nakijin & $33.3(16 / 48)$ & $96.4(27 / 28)$ & $98.3(58 / 59)$ & $17.0(8 / 47)$ \\
\hline Tokunoshima & $28.1(9 / 32)$ & $95.6(65 / 68)$ & $90.7(78 / 86)^{*}$ & $14.1(9 / 64)^{*}$ \\
\hline Kagoshima & $25.0(4 / 16)$ & $94.1(64 / 68)$ & $98.9(89 / 90)$ & $16.2(12 / 74)^{*}$ \\
\hline Ainu & $28.3(15 / 53)$ & $88.0(44 / 50)$ & $84.7(61 / 72)^{* * * \#}$ & $18.2(6 / 33)$ \\
\hline Atayal & $45.8(27 / 59)^{* *}$ & 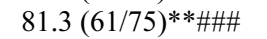 & $95.9(94 / 98)$ & $22.2(16 / 72)$ \\
\hline Afghanistan & $74.4(29 / 39)^{* * * \# \# ~}$ & 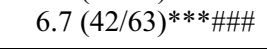 & $65.9(58 / 88) * * * \# \# \#$ & $22.0(9 / 41)$ \\
\hline Population & $\begin{array}{l}\text { Accessory cusp } \\
(\mathrm{LP} 1) \%(\mathrm{~A} / \mathrm{O})\end{array}$ & $\begin{array}{c}\text { Protostylid } \\
(\mathrm{LM} 1) \%(\mathrm{~A} / \mathrm{O})\end{array}$ & $\begin{array}{l}\text { Deflecting wrinkle } \\
\text { (LM1) \% (A/O) }\end{array}$ & $\begin{array}{l}\text { Distal trigonid crest } \\
(\mathrm{LM} 1) \%(\mathrm{~A} / \mathrm{O})\end{array}$ \\
\hline Miyako & $9.1(18 / 198)$ & $4.0(7 / 174)$ & $56.4(22 / 39)$ & $16.7(6 / 36)$ \\
\hline Ishigaki & $12.6(18 / 143)$ & $9.6(12 / 125)$ & $39.7(27 / 68)$ & $10(6 / 60)$ \\
\hline Nakijin & $16.7(10 / 60)$ & $17.0(9 / 53)^{* *}$ & $20.9(9 / 43)^{* *}$ & $8.3(3 / 36)$ \\
\hline Tokunoshima & $3.5(3 / 85) \#$ & $18.5(5 / 27)^{*}$ & $31.3(5 / 16)$ & $8.3(1 / 12)$ \\
\hline Kagoshima & $11.6(10 / 86)$ & $35.3(6 / 17) * * * \# \#$ & $40.0(2 / 5)$ & $66.7(2 / 3) \#$ \\
\hline Tokyo & $9.6(10 / 104)$ & $19.6(19 / 97) * * * \#$ & $33.8(27 / 80)^{*}$ & $13.7(10 / 73)$ \\
\hline Ainu & $0.0(0 / 76) * \# \#$ & $9.5(6 / 63)$ & $32.7(17 / 52)^{*}$ & $6.8(3 / 44)$ \\
\hline Atayal & $6.3(6 / 95)$ & $19.6(9 / 46)^{* *}$ & $32.4(11 / 34)$ & $12.5(4 / 32)$ \\
\hline Afghanistan & $2.3(2 / 89) * \# \#$ & $6.5(2 / 31)$ & $33.3(8 / 24)$ & $3.9(1 / 26)$ \\
\hline Population & $\begin{array}{c}\text { Cusp } 6 \\
(\mathrm{LM} 1) \%(\mathrm{~A} / \mathrm{O})\end{array}$ & $\begin{array}{c}\text { Cusp } 7 \\
(\mathrm{LM} 1) \%(\mathrm{~A} / \mathrm{O})\end{array}$ & $\begin{array}{l}\text { Y groove pattern } \\
(\mathrm{LM} 2) \%(\mathrm{~A} / \mathrm{O})\end{array}$ & $\begin{array}{l}\text { Hypoconulid } \\
\text { (LM2) \% (A/O) }\end{array}$ \\
\hline Miyako & $22.2(10 / 45)$ & $5.9(8 / 136)$ & $10.7(11 / 103)$ & $68.2(73 / 107)$ \\
\hline Ishigaki & $16.4(12 / 73)$ & $7.3(8 / 109)$ & $4.0(4 / 99)$ & $67.1(49 / 73)$ \\
\hline Kadena & $44.2(46 / 104) * \# \# \#$ & $2.8(3 / 109)$ & $27.4(23 / 84)^{* * \# \# \# ~}$ & $63.7(65 / 102)$ \\
\hline Nakijin & $30.8(16 / 52)$ & $1.8(1 / 55)$ & $22.2(2 / 9)$ & $65.0(26 / 40)$ \\
\hline Tokunoshima & 42.1 (16/38)\#\# & $10.8(4 / 37)$ & $50.0(3 / 6) * \# \#$ & $78.4(40 / 51)$ \\
\hline Kagoshima & $26.5(9 / 34)$ & $2.6(1 / 39)$ & $0.0(0 / 4)$ & $73.7(42 / 57)$ \\
\hline Afghanistan & $0.0(0 / 26)^{* \#}$ & $7.6(4 / 53)$ & $22.0(9 / 41) \# \#$ &  \\
\hline
\end{tabular}

Numbers in parentheses show the affected/observed sample number.

Miyako: $* p<0.05,{ }^{*} p<0.01, * * * p<0.001$.

Ishigaki: $\# p<0.05$, \#\# $p<0.01$, \#\#\# $p<0.001$. 


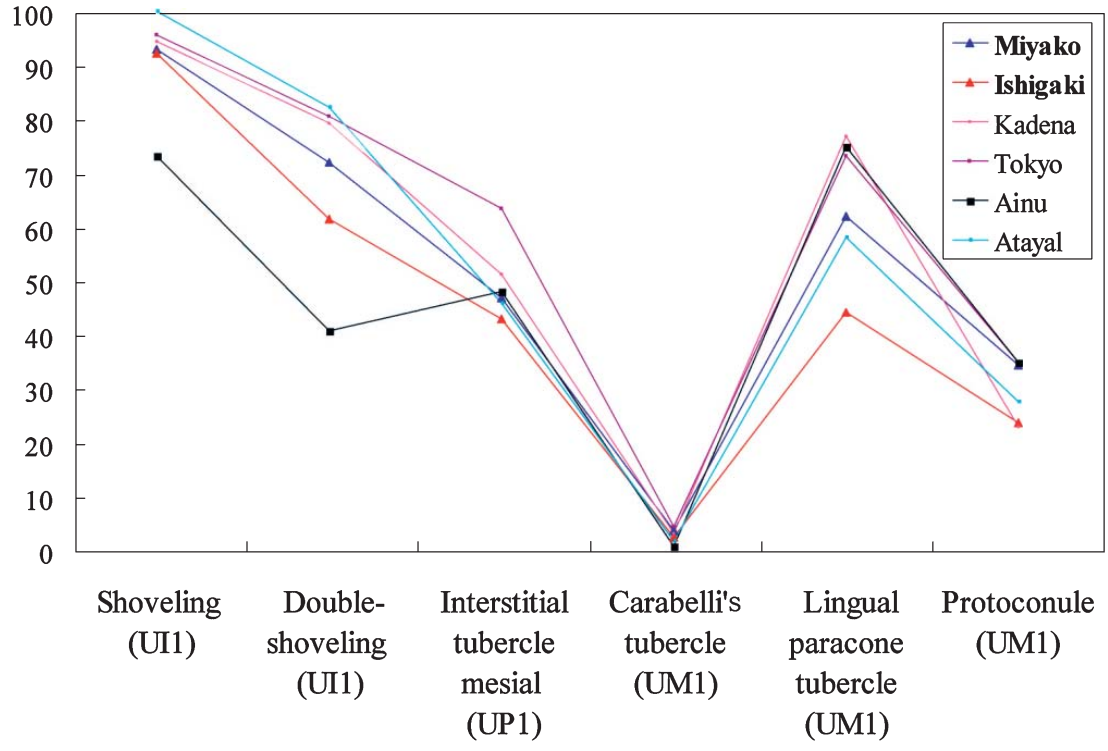

Figure 2. Frequency patterns of the six non-metric dental crown traits in the six samples (I).

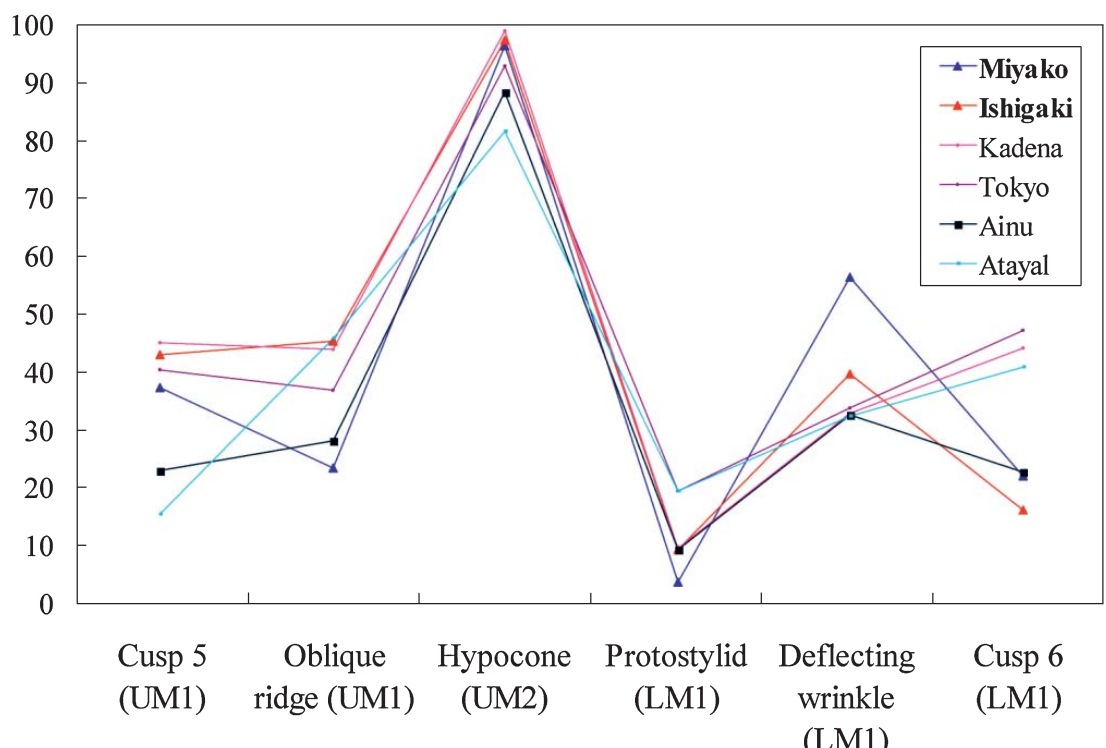

Figure 3. Frequency patterns of the six non-metric dental crown traits in the six samples (II).

Table 3. The MMD (lower diagonal) and standard deviation (upper diagonal) matrices obtained from the 18 non-metric tooth crown traits

\begin{tabular}{llccccccccc}
\hline & Miyako & Ishigaki & Kadena & Nakijin & $\begin{array}{c}\text { Tokuno- } \\
\text { shima }\end{array}$ & Kagoshima & Tokyo & Ainu & Atayal & Afghanistan \\
\hline Miyako & & 0.006 & 0.005 & 0.009 & 0.008 & 0.008 & 0.006 & 0.009 & 0.007 & 0.009 \\
Ishigaki & $0.002^{*}$ & & 0.005 & 0.010 & 0.009 & 0.009 & 0.007 & 0.009 & 0.007 & 0.009 \\
Kadena & 0.018 & 0.030 & & 0.009 & 0.008 & 0.008 & 0.006 & 0.008 & 0.007 & 0.008 \\
Nakijin & $0.007^{*}$ & 0.021 & $0.002^{*}$ & & 0.012 & 0.012 & 0.010 & 0.013 & 0.011 & 0.013 \\
Tokunoshima & 0.016 & 0.035 & $0.008^{*}$ & $0.024^{*}$ & & 0.011 & 0.009 & 0.012 & 0.010 & 0.012 \\
Kagoshima & 0.017 & 0.039 & 0.024 & $0.014^{*}$ & $0.020^{*}$ & & 0.009 & 0.012 & 0.010 & 0.012 \\
Tokyo & 0.023 & 0.043 & $0.005^{*}$ & $0.004^{*}$ & $0.002^{*}$ & $0.002^{*}$ & & 0.010 & 0.008 & 0.010 \\
Ainu & 0.081 & 0.071 & 0.110 & 0.126 & 0.083 & 0.128 & 0.119 & & 0.011 & 0.012 \\
Atayal & 0.048 & 0.082 & 0.053 & 0.047 & 0.048 & 0.046 & 0.030 & 0.148 & & 0.011 \\
Afghanistan & 0.782 & 0.721 & 0.866 & 0.893 & 0.888 & 0.897 & 0.892 & 0.509 & 0.819 & \\
\hline
\end{tabular}

* MMD is not significant at the $5 \%$ level. 


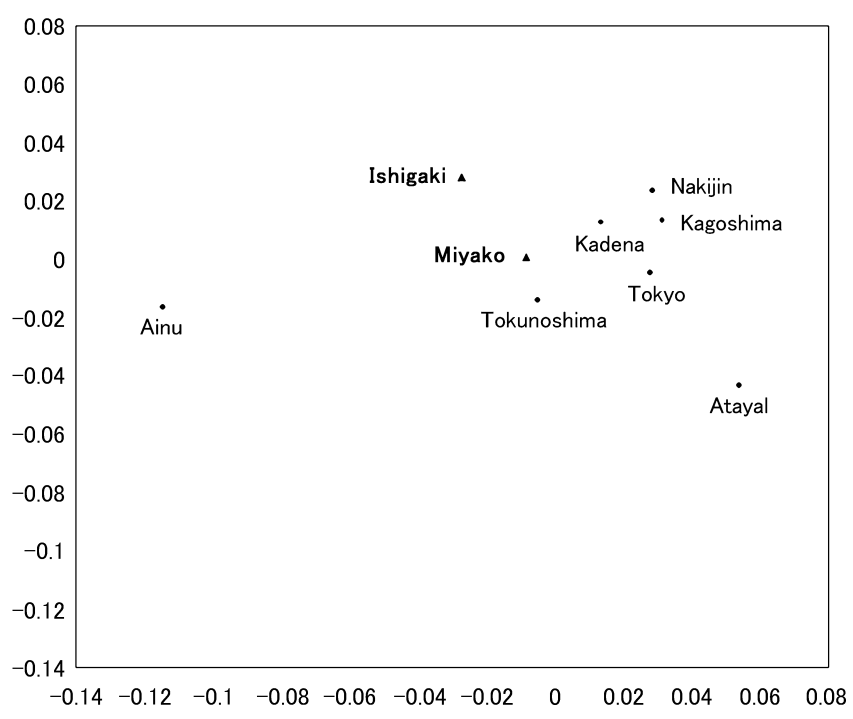

Figure 4. The multidimensional scaling method of the MMD matrix obtained from the 18 non-metric dental crown traits. The Afghanistan sample was excluded from this analysis because of its extreme separation from the other samples based on the MMDs.

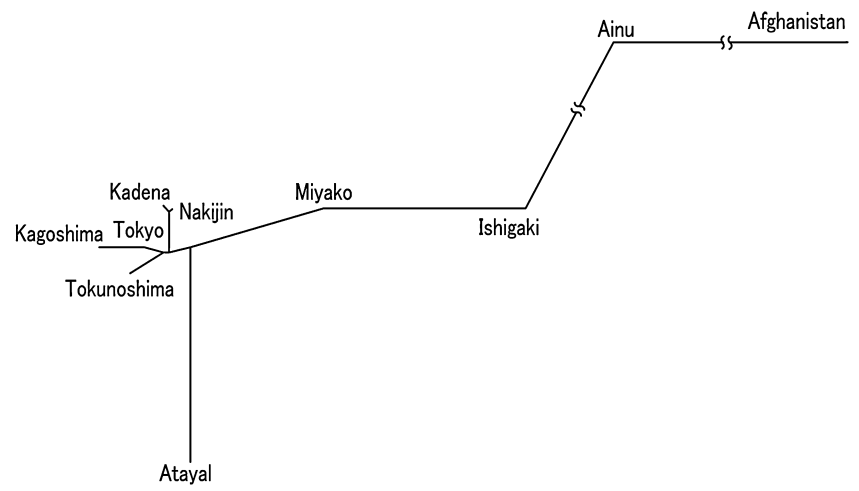

Figure 5. A tree of the 10 population samples using the neighborjoining method applied to the MMD matrix obtained from the 18 nonmetric dental crown traits.

distance matrix to represent an unrooted tree, as shown in Figure 5. The results are generally comparable to those of the multidimensional scaling method. The Afghanistan sam- ple is the most remote. The samples from Kagoshima and Tokyo, and Kadena and Nakijin are connected, respectively. These four populations and the Tokunoshima samples are grouped together. The Ishigaki and Miyako samples are connected with this cluster and there is distance between the Ishigaki-Miyako and the Hokkaido Ainu populations.

Assuming that the samples used in this study have the same effective population size, inter-regional variations were estimated by $F s t$ values. Table 4 shows the minimum Fst, using an average heritability rate $h^{2}=1$, and estimated Fst $\left(h^{2}=0.55\right)$ for the non-metric crown traits. The results show that non-metric dental variations across regions are fairly limited. The Fst value of the five Ryukyu Island samples is larger than that of main-island Japanese.

Table 5 gives the results of using Relethford and Blangero's (1990) method to estimate intra-regional variations, assuming an equal effective population size. Except for the Tokunoshima sample, four samples from the Ryukyu Island chain showed lower phenotypic variation than expected.

Figure 6 shows the multidimensional scaling of distances transformed from the R-matrix. Using the first two dimensions, $92.3 \%$ total variance is expressed. The disposition of the samples is quite similar to Figure 4, based on MMDs.

\section{Discussion}

Ryukyu people, including Miyako and Ishigaki Islanders, are more similar to main-island Japanese than to Ainu, though are situated between main-island Japanese and Ainu in terms of both MMD and R-matrix methods of non-metric dental trait analysis. This is comparable to previous dental and cranial studies (Dodo et al., 1998, 2000; Higa et al., 2003; Fukumine et al., 2006; and many others), whereas several genetic, cranial, and dental analyses, and viral infection studies, have indicated relatively close relationships between Ryukyuans and Ainu (or Jomon) (Hanihara, 1991; Matsumura 1994; Omoto and Saitou, 1997; Yamashita et al., 2001; Watanabe et al., 2004; Matsumura and Hudson, 2005). However, it is more interesting that the anthropological position of the Ryukyu people consistently lies between Ainu and main-island Japanese, in apparent contradiction to their geographical relationship (Fukumine et al., 2006).

One of the most remarkable results is that, among Ryukyu peoples, Ishigaki and Miyako Islanders are relatively close

Table 4. Fst values of Ryukyu and neighboring populations (inter-regional variation)

\begin{tabular}{|c|c|c|c|c|}
\hline & \multicolumn{2}{|c|}{ Minimum } & \multicolumn{2}{|c|}{ Estimated } \\
\hline & $F s t$ & SE & Fst & SE \\
\hline Main-island Japanese samples* & 0.0066 & 0.0022 & 0.0120 & 0.0021 \\
\hline Japanese Archipelago samples*** & 0.0279 & 0.0022 & 0.0495 & 0.0022 \\
\hline East Asian samples $* * * *$ & 0.0309 & 0.0022 & 0.0547 & 0.0021 \\
\hline All samples & 0.0996 & 0.0034 & 0.1628 & 0.0030 \\
\hline
\end{tabular}

Average heritability of the nonmetric dental traits $=0.55$.

* Tokyo and Kagoshima.

** Miyako, Ishigaki, Kadena, Nakijin, and Tokunoshima.

*** Ryukyu Islands, main-island Japanese, and Ainu.

**** Japanese archipelago and Atayal. 
Table 5. Intraregional variation of the eight populations in the Japanese archipelago

\begin{tabular}{lcccc}
\hline Population & Obs. Var. & Exp. Var. & Residual & S.E. \\
\hline Miyako & 0.2457 & 0.2541 & -0.0084 & 0.0714 \\
Ishigaki & 0.2377 & 0.2521 & -0.0144 & 0.0811 \\
Kadena & 0.2478 & 0.2536 & -0.0057 & 0.0683 \\
Nakijin & 0.2432 & 0.2522 & -0.0090 & 0.0670 \\
Tokunoshima & 0.2552 & 0.2520 & 0.0032 & 0.0633 \\
Kagoshima & 0.2514 & 0.2447 & 0.0067 & 0.0645 \\
Tokyo & 0.2535 & 0.2522 & 0.0012 & 0.0602 \\
Ainu & 0.2729 & 0.2331 & 0.0399 & 0.0926 \\
\hline
\end{tabular}

to Hokkaido Ainu and main-island Japanese. As mentioned above, however, Hanihara (1991) and Manabe et al. (2001, 2003) have already obtained identical or clearer results. Hanihara (1991) showed that early Modern Sakishima people of about 200 years ago were closely related to Jomon, and to the Hirota Yayoi sample from Tanegashima Island, Kagoshima, based on metric and non-metric dental traits in particular. In this study, we used samples from present-day junior high school pupils and eliminated some significant traits, including protostylid, and found that Sakishima people may be similar to the main-island Japanese samples.

On the other hand, metric and non-metric cranial analyses of Sakishima samples showed inconsistent results. Some non-metric cranial studies have showed that Sakishima Islanders are farther from Jomon and Ainu people than Okinawa main islanders (Dodo et al., 1998; Fukumine et al., 2006), while Mouri (1986) reported the reverse relationship, probably because of differences in the non-metric traits used. The Sakishima samples were slightly closer to Jomon and Ainu than Okinawa through cranial and facial metric analyses (Pietrusewsky, 1999, 2004; Dodo et al., 2000; Dodo, 2000).

Several human genetic studies on Sakishima Islanders have been performed over the last 40 years (Nakajima et al., 1967; Omoto et al., 1973, 1975; Omoto, 1978; Ago et al., 1998a, b). Omoto (1978) reported that Okinawans are relatively close to main-island Japanese, while the Yaeyama populations of Ishigaki and Iriomote Islands have close affinity to Taiwan Chinese on the basis of 15 polymorphic loci. Ago et al. (1998a, b) pointed out some geographical clines of transferrin and group-specific component/vitamin$\mathrm{D}$ binding protein allele frequencies in southwest Japan and the Ryukyu Island chain and the peculiarity of the Sakishima Islands, Miyako in particular; however, the genetic relationship to Ainu has been little discussed.

Prehistoric Sakishima was located beyond the Jomon culture, as mentioned above (Ikeda, 2005). Turner (1987, 1990), and Scott and Turner (1997), have reported that the morphology of East Asian dentition shows a clinal variation or dichotomy, such as the sundadonty of Southeast Asians and Jomon-Ainu, and the sinodonty of East and Northeast Asians. Ryukyuan dentition, however, was classified either as sundadonty (Matsumura and Hudson, 2005) or sinodonty (Manabe et al., 1999). This inconsistency suggests that the border of the dichotomy is unclear, because each morphological trait has only clinal variation (Hanihara and Ishida, 2001a, b, c, d, e; Higa et al., 2003). This clinal variation of

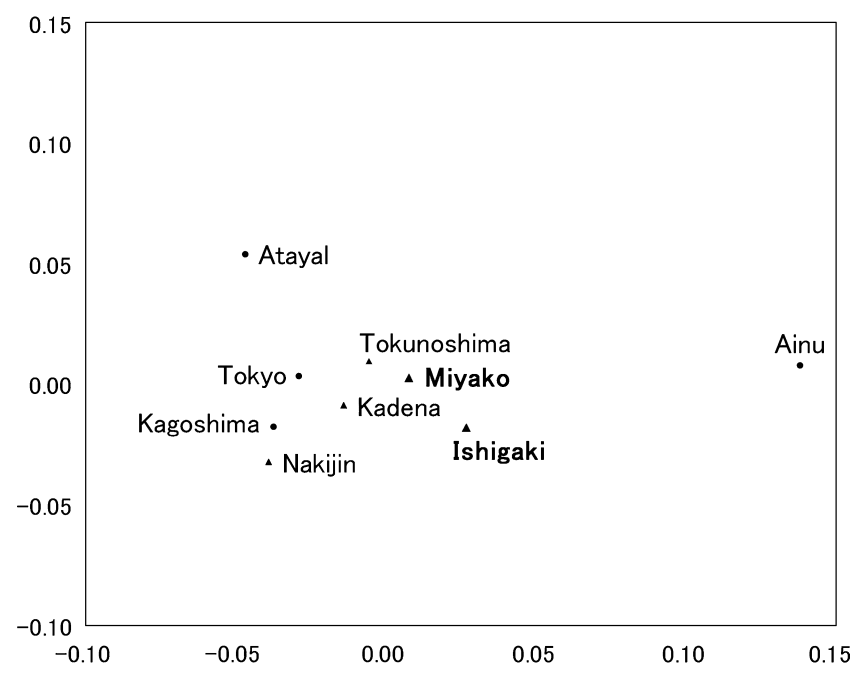

Figure 6. A scattergram of the nine populations, excluding the Afghanistan sample, based on the eigenvectors of the $\mathrm{R}$ matrix.

several dental traits, including double-shoveling, of Sakishima Islanders may result in some affinity between Sakishima Islanders and Hokkaido Ainu because of the more southern location of Sakishima.

In order to clarify if Sakishima people, including Miyako and Ishigaki Islanders, are closer to Ainu than Okinawa Islanders, we will intensively recover prehistoric and historic human skeletal remains from Sakishima and investigate that population via more elaborate genetic analysis.

The estimated Fst and the results of Relethford and Blangero's (1990) method on the basis of non-metric dental traits highlighted some significant aspects of Ryukyuan diversity.

The estimated Fst displayed low levels of inter-regional variation of non-metric dental traits in this study. These findings are more or less consistent with the continued finding of low levels of inter-regional variation reported in studies that used genetic, craniometric and odontometric data (Lewontin, 1972; Latter, 1980; Nei and Roychoudhury, 1982; Ryman et al., 1983; Excoffier et al., 1992; Dean et al., 1994; Barbujani et al., 1997; Seielstad et al., 1998; Jorde et al., 2000; Brown and Armelagos, 2001; Relethford, 2002; Hanihara and Ishida, 2005), whereas skin color showed very high variation among regions, suggesting a natural selection pattern (Relethford, 2002). These results of Fst suggest that non-metric dental variation, when considered as a whole, varies across regions in a manner matching neutral expectations (Relethford and Blangero, 1990). At the very least, inter-regionally differing selection pressures have played a limited role in producing overall patterns of dental diversity.

Some metric and non-metric cranial analyses have shown relative homogeneity in Ryukyuans (Dodo et al., 1998; Pietrusewsky, 1999, 2004), while other cranial and dental analyses resulted in the heterogeneity of the Amami Islands or Sakishima from Okinawa Island (Tagaya and Ikeda, 1976; Mouri, 1986; Hanihara, 1991; Dodo et al., 2000; Higa et al., 2003). Okinawan genetic diversity is comparable to that of main-island Japanese (Hammer and Horai, 1995; Horai et 
al., 1996), although genetic diversity throughout the whole Ryukyu Island chain has not yet been reported. The estimated Fst is larger in Ryukyu people, including Sakishima samples, than in the main-island Japanese in this study. This relatively large diversity suggests the isolation or poor contact between each island throughout history in Ryukyu Islanders.

Next, Relethford and Blangero's (1990) method resulted in four samples from the Ryukyu Island chain showing lesser observed variation than expected, except for Tokunoshima. This indicates that the effective population size in Ryukyu Island chain was less than in mainland Japan. In other words, the results may reflect larger genetic drift in the Ryukyu Island chain. As the Sakishima Islands had been isolated from the Jomon and Yayoi culture in particular (Ikeda, 2005), this suggestion may not be far from the mark.

\section{Acknowledgments}

We wish to thank the principals, N. Tomari, H. Matsubara, T. Sadoyama, and school nurse, T. Sakiyama, the many teachers, pupils and their parents for offering us the chance to collect dental plaster casts in Miyako and Ishigaki. We are also grateful to dentists, M. Ueshiro, T. Ueta, and I. Sunakawa for their cooperation in collecting the dental plaster casts in their dental offices.

This study was supported in part by a Grant-in-aid for Scientific Research (Nos. 14540659, 17202025) from the Japan Society for the Promotion of Science.

\section{References}

Ago K., Yuasa I., and Tsuganezawa O. (1998a) Transferrin polymorphism in the Nansei Islands: distribution of a new variant TF Dama and clines of allele frequencies in Japanese populations. Anthropological Science, 106: 209-219.

Ago K., Yuasa I., and Tsuganezawa O. (1998b) Distribution of group-specific component/vitamin D-binding protein alleles in southwestern Japan and geographic clines of allele frequencies in Japanese populations. Anthropological Science, 106: 385-395.

von Baelz E. (1911) Die Riu-Kiu-Insulaner, die Aino und andere kaukasierähnliche Reste in Ostasien. Korrespondenz-Blatt der Deutschen Gesellschaft für Anthropologie, Ethnologie und Urgeschichte, 42: 187-191.

Barbujani G., Magagni A., Mich E., and Cavalli-Sforza L.L. (1997) An apportionment of human DNA diversity. Proceedings of the National Academy of Sciences of the United States of America, 94: 4516-4519.

Berry A.C. (1978) Anthropological and family studies on minor variants of dental crown. In: Butler P.M. and Joysey K.A. (eds.), Development, Function and Evolution of Teeth. Academic Press, London, pp. 81-98.

Biggerstaff R.H. (1970) Morphological variations for the permanent mandibular first molars in human monozygotic and dizygotic twins. Archives of Oral Biology, 15: 721-730.

Biggerstaff R.H. (1973) Heritability of the Carabelli cusp in twins. Journal of Dental Research, 52: 40-44.

Blanco R. and Chakraborty R. (1977) The genetics of shovel shape in maxillary central incisors in man. American Journal of Physical Anthropology, 44: 233-236.

Blangero J. and Williams-Blangero S. (1993) A quantitative genetic method for calculating genetic distances from dermatoglyphic pattern types. American Journal of Physical
Anthropology, Supplement 16: 59-60.

Brown R.A. and Armelagos G.J. (2001) Apportionment of racial diversity: a review. Evolutionary Anthropology, 10: 34-40.

Dean M., Stephens C., Winkler C., Lomb D.A., Ramsburg M., Boaze R., Stewart C., Charbonneau L., Goldman D., Albough B.J., Goedert J.J., Beasley P., Hwang L-V., Buchbinder S., Weedon M., Johnson P.A., Eichelberger M., and O'Brian S.J. (1994) Polymorphic admixture typing in human ethnic populations. American Journal of Human Genetics, 55: 788-808.

Dodo Y. (2000) Metric method differences of the upper facial height influence analytic results. An example of craniometric study between the Ainu and Ryukyuan. Anthropological Science (Japanese Series), 108: 133-141 (in Japanese).

Dodo Y., Doi N., and Kondo O. (1998) Ainu and Ryukyuan cranial nonmetric variation: evidence which disputes the AinuRyukyu common origin theory. Anthropological Science, 106: 99-120.

Dodo Y., Doi N., and Kondo O. (2000) Flatness of facial skeletons of Ryukyuans. Anthropological Science, 108: 183-198.

Doi N. (2003) Population history of the Ryukyuans as viewed from the human skeletal remains. In: Okinawa Prefectural Culture Promotion Foundation (ed.), Okinawa Prefecture History, Archaeology, Naha, pp. 575-610 (in Japanese).

Excoffier L., Smouse P.F., and Quattro J.M. (1992) Analysis of molecular variance inferred from metric distances among DNA haplotypes: application to human mitochondrial DNA restriction data. Genetics, 131: 479-491.

Fukumine T., Hanihara T., Nishime A., and Ishida H. (2006) Nonmetric cranial variation of early Modern human skeletal remains from Kumejima, Okinawa and the peopling of the Ryukyu Islands. Anthropological Science, 114: 141-151.

González-José R., González-Martin A., Hernández M., Pucciarelli H.M., Sardi M., Rosales A., and Molen S.V. (2003) Craniometric evidence for Palaeoamerican survival in Baja California. Nature, 425: 62-65.

Hallgrímsson B., Donnabháin Ó.B., Walters G.B., Cooper D.M.L., Guðbjartsson D., and Stefánsson K. (2004) Composition of the founding population of Iceland: biological distance and morphological variation in early historic Atlantic Europe. American Journal of Physical Anthropology, 124: 257-274.

Hammer M.F. and Horai S. (1995) Y chromosomal DNA variation and the peopling of Japan. American Journal of Human Genetics, 56: 951-962.

Hammer M.F., Karafet T.M., Parek H., Omoto K., Harihara S., Stoneking M., and Horai S. (2006) Dual origins of the Japanese: common ground for hunter-gatherer and farmer Y chromosomes. Journal of Human Genetics, 51: 47-58.

Hanihara K. (1991) Dual structure model for the population history of the Japanese. Japan Review, 2: 1-33.

Hanihara K., Masuda T., and Tanaka T. (1974) Affinities of dental characteristics in the Okinawa Islanders. Journal of Anthropological Society of Nippon, 82: 75-82.

Hanihara K., Masuda T., and Tanaka T. (1975) Family studies of the shovel trait in the maxillary central incisor. Journal of the Anthropological Society of Nippon, 83: 107-112.

Hanihara T. (1991) Dentition of Nansei Islanders and peopling of the Japanese Archipelago: the basic populations in East Asia, IX. Journal of Anthropological Society of Nippon, 99: 399409.

Hanihara T. and Ishida H. (2001a) Os incae: frequency variation in major human population groups. Journal of Anatomy, 198: $137-152$.

Hanihara T. and Ishida H. (2001b) Frequency variations of discrete cranial traits in major human populations. I. Supernumerary ossicle variations. Journal of Anatomy, 198: 689-706.

Hanihara T. and Ishida H. (2001c) Frequency variations of discrete cranial traits in major human populations. II. Hypostotic variations. Journal of Anatomy, 198: 707-725.

Hanihara T. and Ishida H. (2001d) Frequency variations of discrete 
cranial traits in major human populations. III Hyperostotic variations. Journal of Anatomy, 199: 251-272

Hanihara T. and Ishida H. (2001e) Frequency variations of discrete cranial traits in major human populations. IV Vessels and nerve related variations. Journal of Anatomy, 199: 273-287.

Hanihara T. and Ishida H. (2005) Metric dental variation of major human populations. American Journal of Physical Anthropology, 128: 287-298.

Hanihara T., Ishida H., and Dodo Y. (2003) Characterization of biological diversity through analysis of discrete cranial traits. American Journal of Physical Anthropology, 121: 241-251.

Harpending H.C. and Ward R. (1982) Chemical systematics and human evolution. In: Nitecki M. (ed.), Biochemical Aspects of Evolutionary Biology, University of Chicago Press, Chicago, pp. 213-256.

Hatta Y., Ohashi J., Imanishi T., Kamiyama H., Iha M., Shimabukuro T., Ogawa A., Tanaka H., Akaza T., Gojobori T., Juji T., and Tokunaga K. (1999) HLA genes and haplotypes in Ryukyuans suggest recent gene flow to the Okinawa Islands. Human Biology, 71: 353-365.

Hawks F.L. and Perry M.C. (1856) Narrative of the expedition of an American squadron to the China seas and Japan: performed in the years 1852, 1853, and 1854, under the command of Commodore M.C. Perry, United States Navy, by order of the Government of the United States. The Congress of the United States, Washington DC.

Higa T., Hanihara T., Sunakawa H., and Ishida H. (2003) Dental variation of Ryukyu Islanders: a comparative study among Ryukyu, Ainu and other Asian populations. American Journal of Human Biology, 15: 127-143.

Hillson S. (1996) Dental Anthropology. Cambridge University Press, Cambridge.

Horai S., Maruyama K., Hayasaka K., Matsubayashi S., Hattori Y., Fucharoen S., Harihara S., Kyung S.P., Omoto K., and I-Hung P. (1996) mtDNA polymorphism in East Asian populations, with special reference to the peopling of Japan. American Journal of Human Genetics, 59: 579-590.

Ikeda J. (1974) Craniometry of Miyako Islanders, the Ryukyus. Journal of Anthropological Society of Nippon, 82: 150-160 (in Japanese with English summary).

Ikeda J. (1998) Nihonjin no kita michi. [The Roots of the Japanese.] Asahi shinbun sha, Tokyo (in Japanese).

Ikeda Y. (2005) Formation of Ryukyu culture. In: Tomiyama K. and Takara K. (eds.), Ryukyu, Okinawa and Route along the Coast. Yoshikawa Kobunkan, Tokyo, pp. 56-61 (in Japanese).

Jorde L.B., Watkins W.S., Bamshad M.J., Dixon M.E., Ricker C.E., Seielstad M.T., and Batzer M.A. (2000) The distribution of human genetic diversity: a comparison of mitochondrial, autosomal, and Y-chromosome data. American Journal of Human Genetics, 66: 979-988.

Latter B.D.H. (1980) Genetic differences within and between populations of the major human subgroups. American Naturalist, 116: 220-237.

Leigh S.R. and Konigsberg L.W. (1996) Intraspecific discrete trait polymorphism in African apes: implications for variation in the fossil record. American Journal of Physical Anthropology, Supplement 22: 147

Leigh S.R., Relethford J.H., Park P.B., and Konigsberg L.W. (2004) Morphological differentiation of Gorilla subspecies. In: Taylor A.B. and Goldsmith M.L. (eds.), Gorilla Biology: A Multidisciplinary Perspective. Cambridge University Press, Cambridge, pp. 104-131.

Lewontin R. (1972) The apportionment of human diversity. Evolutionary Biology, 6: 381-398.

Manabe Y., Kitagawa Y., Oyamada J., Kato K., Ito R., Kobayashi S., and Rokutanda A. (1999) Genealogical positioning of the Okinawa main islanders in East Asian populations based on nonmetric tooth crown traits. Anthropological Science, 107:
85.

Manabe Y., Kitagawa Y., Oyamada J., Kato K., Ito R., Kobayashi S., and Rokutanda A. (2001) Population history of the Ryukyu Islanders in Japan as viewed from dental morphology. 3. The modern inhabitants of the Ishigaki Island. Anthropological Science, 109: 110.

Manabe Y., Ito R., Kikuchi N., Kitagawa Y., Oyamada J., Tsutsumida A., Kato K., Rokutanda A., and Kobayashi S. (2003) Population history of the Ryukyu Islanders in Japan as viewed from dental morphology. 4. The modern inhabitants of the Miyako Island. Anthropological Science, 111: 423.

Matsumura H. (1994) A microevolutional history of the Japanese people from a dental characteristics perspective. Anthropological Science, 102: 93-118.

Matsumura H. and Hudson M. (2005) Dental perspectives on the population history of Southeast Asia. American Journal of Physical Anthropology, 127: 182-209.

Mizoguchi Y. (1977) Genetic variability in tooth crown characters: analysis by the tetrachoric correlation method. Bulletin of the National Science Museum, Series D, 3: 37-62.

Mouri T. (1986) Geographical and temporal variation in Japanese populations as viewed from nonmetric traits of the skull. $\mathrm{PhD}$ thesis, Kyoto University, pp. 1-79 (in Japanese).

Nagaoka T. and Hirata K. (2006) Tooth size of the medieval period people of Japan. Anthropological Science, 114: 117-126.

Nakajima H., Ohkura K., Inafuku S., Ogura Y., Koyama T., Hori F., and Takahara S. (1967) The distribution of several serological and biochemical traits in east Asia. II. The distribution of ABO, MNSs, Q, Lewis, Rh, Kell, Duffy and Kidd blood groups in Ryukyu. The Japanese Journal of Human Genetics, 12: $29-37$

Nei M. and Roychoudhury A.K. (1982) Genetic relationship and evolution of human races. Evolutionary Biology, 14: 1-59.

Omoto K. (1978) Genetic polymorphism of the Japanese. In: Ikeda J. (ed.), The Japanese II. Anthropology 6. Yuzankaku Press, Tokyo, pp. 217-263 (in Japanese).

Omoto K. and Saitou N. (1997) Genetic origins of the Japanese: a partial support for the dual structure hypothesis. American Journal of Physical Anthropology, 102: 437-446.

Omoto K., Ishizaki K., Harada S., Akaishi S., Kudo T., and Takahashi K. (1973) The distribution of serum protein and red cell enzyme types among blood donors of Okinawa Is., the Ryukyus. Journal of the Anthropological Society of Nippon, 81: 159-173.

Omoto K., Ishimoto G., Harda S., and Misawa S. (1975) The distribution of genetic markers in blood samples from Okinawa, the Ryukyus. II. The distribution of several red cell enzyme types in Ishigaki Islands. Journal of the Anthropological Society of Nippon, 83: 253-260.

Ossenberg N.S., Dodo Y., Maeda T., and Kawakubo Y. (2006) Ethnogenesis and craniofacial change in Japan from the perspective of nonmetric traits. Anthropological Science, 114: 99115.

Pietrusewsky M. (1999) A multivariate craniometric study of the inhabitants of the Ryukyu Islands and comparisons with cranial series from Japan, Asia, and the Pacific. Anthropological Science, 107: 255-281.

Pietrusewsky M. (2004) Multivariate comparisons of female cranial series from the Ryukyu Islands and Japan. Anthropological Science, 112: 199-211.

Powell J.F. and Neves W.A. (1999) Craniofacial morphology of the first Americans: pattern and process in the peopling of the New World. Yearbook of Physical Anthropology, 42: 153188.

Relethford J.H. (1991) Genetic drift and anthropometric variation in Ireland. Human Biology, 63: 155-165.

Relethford J.H. (1994) Craniometric variation among modern human populations. American Journal of Physical Anthropology, 95: 53-62. 
Relethford J.H. (2002) Apportionment of global human genetic diversity based on craniometrics and skin color. American Journal of Physical Anthropology, 118: 393-398.

Relethford J.H. and Blangero J. (1990) Detection of differential gene flow from patterns of quantitative variation. Human Biology, 62: 5-25.

Relethford J.H. and Harpending H.C. (1994) Craniometric variation, genetic theory, and modern human origins. American Journal of Physical Anthropology, 95: 249-270.

Roseman C.C. and Weaver T.D. (2004) Multivariate apportionment of global human craniometric diversity. American Journal of Physical Anthropology, 125: 257-263.

Ryman N., Chakraborty R., and Nei M. (1983) Differences in the relative distribution of human gene diversity between electrophoretic and red and white cell antigen loci. Human heredity, 33: $93-10$

Saitou N. (2005) Japanese as Viewed from DNA. Chikuma Shobo, Tokyo (in Japanese).

Saitou N. and Nei M. (1987) The neighbor-joining method: a new method for reconstructing phylogenetic trees. Molecular Biology and Evolution, 4: 406-425.

Sakura H. (1985) Pleistocene human fossil remains from PinzaAbu (Goat Cave), Miyako Island, Okinawa, Japan. In: Report on Excavaton of the Pinza-Abu Cave. Department of Education, Okinawa Prefectural Government, Naha, pp. 161-176.

Sakura H. (1988) Additional finding of Pleistocene infant bones excavated at Shimojibaru Cave, Kume Island, Okinawa. Journal of the Anthropological Society of Nippon, 96: 202.

Schilacii M.A. and Stojanowski C.M. (2005) Craniometric variation and population history of the prehistoric Tewa. American Journal of Physical Anthropology, 126: 404-412.

Scott G.R. and Potter R.H.Y. (1984) An analysis of tooth crown morphology in American white twins. Anthropologie, 22: 223-231.

Scott G.R. and Turner C.G. II. (1997) The Anthropology of Modern Human Teeth: Dental Morphology and its Variation in Recent Human Populations. Cambridge University Press, Cambridge.

Seielstad M.T., Minch E., and Cavalli-Sforza L.L. (1998) Genetic evidence for a higher female migration rate in humans. Nature Genetics, 20: 278-280.

Sjøvold T. (1973) The occurrence of minor non-metrical variants in the skeleton and their quantitative treatment for population comparisons. Homo, 24: 204-233.

Sneath P.H.A. and Sokal R.R. (1973) Numerical Taxonomy. W.H. Freeman, San Francisco.

Sofaer J.A., MacLean C.J., and Bailit H.L. (1972) Heredity and morphological variation in early and late developing human teeth of the same morphological class. Archives of Oral Biology, 17: 811-816.

Steadman D.W. (2001) Mississippians in motion? A population genetic analysis of interregional gene flow in West-Central Illinois. American Journal of Physical Anthropology, 114: 61-73.

Stojanowski C.M. (2004) Population history of Native groups in pre- and postcontact Spanish Florida: aggregation, gene flow, and genetic drift on the southeastern US Atlantic coast. American Journal of Physical Anthropology, 123: 316-332.

Stojanowski C.M. (2005) Spanish colonial effects on Native American mating structure and genetic variability in northern and central Florida: evidence from Apalachee and western Timucua. American Journal of Physical Anthropology, 128: 273-286.

Suzuki H. and Hanihara K. (eds.) (1982) The Minatogawa ManThe Upper Pleistocene Man from the Island of Okinawa. University of Tokyo Press, Tokyo.

Tagaya A. and Ikeda J. (1976) A multivariate analysis of the cranial measurements of the Ryukyu Islanders (male). Journal of the Anthropological Society of Nippon, 84: 204-220.

Townsend G.C., Rchiards L.C., Brown T., Burgess V.B., Travan G.R., and Rogers J.R. (1992) Genetic studies of dental morphology in South Australian twins. In: Smith P. and Tchernov E. (eds.), Structure, Function and Evolution of Teeth. Freund, London, pp. 501-518.

Turner C.G. II (1987) Late Pleistocene and Holocene population history of East Asia based on dental variation. American Journal of Physical Anthropology, 73: 305-321.

Turner C.G. II (1990) Major features of sundadonty and sinodonty, including suggestions about East Asian microevolution, population history, and late Pleistocene relationships with Australian aboriginals. American Journal of Physical Anthropology, 82: 295-317.

Umetsu K., Tanaka M., Yuasa I., Adachi N., Miyoshi A., Kashimura S., Park KS., Wei YH., Watanabe G., and Osawa M. (2005) Multiplex amplified product-length polymorphism analysis of 36 mitochondrial single-nucleotide plymorphisms for haplogrouping of East Asian populations. Electrophoresis, 26: $91-98$

Yamashita M., Ishida T., Ohkura S., Miura T., and Hayami M. (2001) Phylogenetic characterization of a new HTLV type 1 from the Ainu in Japan. AIDS Research and Human Retroviruses, 17: 783-787.

Watanabe T., Saiki K., Okamoto K., and Wakebe T. (2004) Metrical and nonmetrical analyses of modern female crania in the northwestern Kyushu area. Anthropological Science, 112: 147-159.

Erratum:

Page 39, right column, lines 1, 2, and 3 .

Now the listed numbers are:

$0.00071,0.00081$, and 0.00083 .

These should be:

$0.0071,0.0081$, and 0.0083 . 